\title{
Frequency of Convergence Insufficiency in a Refraction Clinic of Karachi
}

\author{
Izmal Urooj ${ }^{1}$, Shari Mussadiq Ali $^{2}$, Abdul Ghayas ${ }^{3}$, Ammara Sheikh $^{4}$, Maryam Hussain \\ ${ }^{1-5}$ Isra School of Optometry, Isra University, Karachi
}

\begin{abstract}
Purpose: To find out the frequency of convergence insufficiency in a refraction clinic of Karachi.

Study Design: Cross Sectional Study.

Place and Duration of Study: Al-lbrahim Rye Hospital, Karachi from June to December 2019.

Methods: A total of 150 patients were included in the study (52 males and 98 females). Patients with uncorrected visual acuity of $\geq 6 / 9$ and age between $16-35$ years were included. Patients who had received treatment for convergence insufficiency $(\mathrm{Cl})$, mentally retarded patients, patients with Manifest strabismus or any other ocular pathology were excluded. Near point of convergence (NPC), near phoria and positive fusional vergence (PFV) were measured for the diagnosis of $\mathrm{Cl}$.

Results: Mean age of the patients was 23.55 years. Gender wise distribution showed that $52(34.7 \%)$ were males and $98(65.3 \%)$ were females. Out of 150 patients, 64 patients had $\mathrm{Cl}$ and 42 were normal with no reduction in NPC, PFV or exophoria. Rest of the patients had only one of the three criteria of $\mathrm{Cl}$ but did not qualify our definition of $\mathrm{Cl}$. Twenty-five male patients and 39 female patients had $\mathrm{Cl}$. $\mathrm{Cl}$ was more common in teenagers. With increasing age, the frequency of $\mathrm{Cl}$ was reduced. $\mathrm{Cl}$ due to remote NPC was seen in $12(8 \%)$ and $\mathrm{Cl}$ due to decreased PFV was seen in 21 (14\%).
\end{abstract}

Conclusion: Females are affected more with $\mathrm{Cl}$ than males especially in the younger age group.

Keywords: Convergence insufficiency, near point of convergence, Positive fusional vergence.

How to Cite this Article: Urooj I, Talpur AH, Ali SM, Ghayas A, Sheikh A. Frequency of Convergence Insufficiency in a Refraction Clinic of Karachi. Pak J Ophthalmol. 2021, 37 (1): 66-69.

Doi: https://doi.org/10.36351/pjo.v37i1.1131

\section{INTRODUCTION}

Convergence insufficiency (CI) was first described by Von Graefein 1855 and later details were given by Duane. ${ }^{1}$ Evans defined $\mathrm{CI}$ as a condition that involves the inability of the eyes to obtain or maintain sufficient convergence for comfortable binocular vision at near distance. ${ }^{2}$ Convergence insufficiency is a typical condition in young and aging adults and may be

Correspondence: Izmal Urooj

Isra School of Optometry, Isra University Karachi

Email: izmalurooj@gmail.com

Received: September 16, 2020

Accepted: November 12, 2020 isolated and idiopathic or associated with other neurologic diseases. ${ }^{3}$ It can cause problem in reading, for which parents or teachers might think of the child having problem in learning rather than having an eye disorder. ${ }^{4}$ It is characterized by exophoria that is greater at near than at distance, a remote near point of convergence (NPC) or decreased positive fusional vergence (PFV) at near. ${ }^{5}$

Near visual tasks such as reading can prompt the symptoms of convergence insufficiency. If near work is continued for a long time, the symptoms are increased. Extreme tiredness (fatigue) can also generate symptoms. The potential symptoms include; headache, double vision, eye fatigue, blurred vision, sleepiness when reading, needing to re-read things a few times, trouble concentrating on reading, words 
seem to move, jump, or float on the page, motion sickness and/or vertigo. Some people may also observe moving of one eye outwards while reading. The person may close one eye while reading to avoid double vision. ${ }^{6}$

Young adults commonly present with CI despite the fact that it can be present almost at any age. Although $1 \%$ of the general population presents with exodeviation, the incidence of CI is estimated to be 0.1 to $0.2 \%$ and $11-19 \%$ of children with exodeviation have CI. The prevalence of $\mathrm{CI}$ in the pediatric and young adults ranges from 2.25 to $8.3 \%$. $^{7}$ The prevalence of convergence insufficiency in United States ranges from $2.25 \%$ to $8.30 \%$ in adults and children respectively. ${ }^{8}$ A survey conducted in Britain showed 1 in 300 children had CI, ${ }^{9}$ and one in 100 of the symptomatic patients had CI in a study conducted in Spain. ${ }^{10} \mathrm{~A}$ study conducted in the Romanian population showed that 3 in $5(60.4 \%)$ adolescents who complained of blurred vision while performing near task had CI. ${ }^{11}$ In Iranian population CI was found to be $5.46 \% .{ }^{12}$ However, it was $16.5 \%$ and $17.6 \%$ in Indian urban and rural arms, respectively. ${ }^{13}$ With effective conservative therapies, prognosis of $\mathrm{CI}$ is excellent in most of the patients. In order to restore CI a small percentage of patients may require surgery. ${ }^{14}$

The purpose of this study was to find out the frequency of convergence insufficiency in a refractive clinic of Karachi.

\section{METHODS}

A cross sectional study with non-probability convenient sampling technique was conducted on 150 patients at al Ibrahim Eye Hospital Malir Karachi during a span of 6 months to determine the frequency of convergence insufficiency. Patients with uncorrected visual acuity greater than or equal to $6 / 9$ and age between 16 - 35 years were included in the study and those having any ocular pathology or manifest strabismus were excluded from the study.

After taking consent the patient's history was taken. Test performed included visual acuity, refraction, near point of convergence (measured using the RAF ruler), exophoria at near (measured using Maddox wing) and positive fusional vergence (measured with prism bar). Those patients who had any two of the following criteria were regarded to have Convergence Insufficiency. NPC > $10 \mathrm{~cm}, \mathrm{PFV}<15$ prism diopter (Base Out) and Exophoria > 4 prism diopters.

Statistical analysis was done from statistical package for social science (SPSS) version 20.0 all the continuous variables were presented as Mean \pm SD and the entire categorical data was presented as frequency and percentage.

\section{RESULTS}

Mean age of the patients was 23.55 years. Gender wise distribution showed that $52(34.7 \%)$ were males and $98(65.3 \%)$ were females. Out of 150 patients, 64 $(42.6 \%)$ patients had CI and $42(28 \%)$ were normal with no reduced NPC, PFV or exophoria. Rest of the patients had only one of the three criteria of CI but did not qualify our definition of CI. Twenty-five male patients and 39 female patients had CI. CI was more common in teenagers. With increasing age, the frequency of CI was reduced. CI due to remote NPC was seen in $12(8 \%)$ and CI due to decreased PFV was seen in $21(14 \%)$. For details see table 1.

Table 1: Parameter of convergence insufficiency with percentage.

\begin{tabular}{lr}
\hline Parameter & Percentage \\
\hline NPC $<10 \mathrm{~cm}$ & $101(67.3 \%)$ \\
NPC $>10 \mathrm{~cm}$ & $49(32.7 \%)$ \\
PFV $<15$ prism diopters & $82(54.7 \%)$ \\
PFV $>15$ prism diopters & $68(45.3 \%)$ \\
Exophoria of $<4$ Prism Diopters & $98(65.3 \%)$ \\
Exophoria $>4$ Prism Diopters & $52(34.7 \%)$ \\
\hline
\end{tabular}

\section{DISCUSSION}

Vergence anomalies have become more troublesome in the current times as computer usage and near tasks have increased over the past few decades. CI is the most predominant and treatable form of vergence anomaly. Patients with CI develop ocular fatigue due to breakdown of binocular vision leading to asthenopia during near tasks.

A study conducted in Iran on the students of Iran University of medical sciences showed that $10 \%$ of the students had CI disorder out of which $7.5 \%$ had CI and $2.5 \%$ were pseudo CI. ${ }^{15}$ Our percentage was quite higher than Iranian study. Another study that was conducted in India showed that $27.5 \%$ of the population had $\mathrm{CI}^{16}$ and a study conducted in china showed CI to be present in $9.6 \%$ of the patients. ${ }^{17}$ 
This study demonstrated that more CI patients displayed reduced NPC and PFV than only reduced NPC or PFV. CI due to remote NPC was seen in 12 (8\%) and CI due to decreased PFV was seen in 21 (14\%). This contrasted with the findings of a previous study that was conducted in Sudan in which $20.36 \%$ of students with CI had reduced NPC and CI due to reduced PFV was seen in $1.22 \%$ of the students. ${ }^{18}$

In this study CI was seen in $42.6 \%$ in which males were $25(39 \%)$ and females were 39 (60.90\%). A study conducted in Mashhad city of Iran showed that 5.51\% of the population had CI out of which $4.78 \%$ was seen in males and $5.86 \%$ in females. This shows that females are affected more than male and also there is a large gap in the percentage of CI in both the studies.

The discrepancies in the reported CI may be due to differences in the definition of CI (in this study CI was defined on 3 diagnostic criteria and the study mentioned above used 4 diagnostic criteria). The other reason could be the sample population. The study mentioned was a general population study and this study was a clinical study. The above study used cluster sampling but we used convenient sampling in our study. Different methods of analysis and differences in testing protocols (in this study NPC was measured using the RAF ruler while the study mentioned used scale to measure the NPC) can also be the reasons for difference in the results. As it is mostly symptomatic patients who present to clinics, such studies are expected to find higher rates compared to population-based studies. ${ }^{19,20}$

Limitation of our study is that it was a clinic-based study. The results cannot be regarded as a true picture of general population. The sample size was small and it was a single-centered research.

\section{CONCLUSION}

Convergence insufficiency is quite high in patients presenting in the refraction clinic. Females are affected more than males regarding $\mathrm{CI}$.

\section{Ethical Approval}

The study was approved by the institutional review board/ethical review board. (REC/IPIO/2020/008)

\section{Conflict of Interest}

Authors declared no conflicts of interest.

\section{REFERENCES}

1. Von Graefe A. Uber myopia in distansnebstbetrachtungen uber sehenjenseits der grenzenunserer (Accommodation). Graefes Arch Clin Exp Ophthalmol. 1855; 2: 158-166.

2. Evans BJ. Decompensated exophoria at near, convergence insufficiency and binocular instability: Diagnosis and the development of a new treatment regimen. In: Evans B, Doshi S, editors. Binocular Vision and Orthoptics. Oxford: ButterworthHeinemann; 2001: p. 39-49.

3. Sassonov O, Sassonov Y, Koslowe K, Shneor E. The Effect of Test Sequence on Measurement of Positive and Negative Fusional Vergence. Optometry and Vision Development, 2010; 41 (1):

https://cdn.ymaws.com/www.covd.org/resource/resmgr/ ovd41-1/article_effecttestsequence.pdf

4. Ghadban R, Martinez JM, Diehl NN, Mohney BG. The incidence and clinical characteristics of adult-onset convergence insufficiency. Ophthalmology, 2015; 122 (5): 1056-9. Doi: 10.1016/j.ophtha.2014.12.010.

5. Scheiman M, Wick B. Clinical Management of Binocular Vision: Heterophoric, Accommodative and Eye Movement Disorders 2014. Philadelphia: Lippincott, Williams, and Wilkins; 2014.

6. Rouse MW, Hyman L, Hussein M, Solan H. CIRS group Frequency of convergence insufficiency in optometry clinic settings. Optom Vis Sci. 1998; 75: 8896.

7. Gregory I, Gappy C, Monte AD, Al-Hashimi R. Convergence Insufficiency. https://eyewiki.aao.org/Convergence_Insufficiency\#Pre valence.C2.A0 (accessed 10 September 2019).

8. Scheiman M, Cooper J, Mitchell GL, Paul de L, Cotter S, Borsting E, et al. A survey of treatment modalities for convergence insufficiency, 2002; 79 (3): 151-157. https://pubmed.ncbi.nlm.nih.gov/11913841/

9. Stidwill D. Epidemiology of strabismus. Ophthalmic Physiol Opt. 1997; 17: 536-539.

10. Lara F, Cacho P, García A, Megías R. General binocular disorders: Prevalence in a clinic population. Ophthalmic Physiol Opt. 2001; 21: 70-74.

11. Dragomir M, Truş L, Chirilă D, Stîngu C. Orthoptic treatment efficiency in convergence insufficiency treatment. Oftalmologia 2001; 53: 66-69.

12. Hashemi H, Nabovati $\mathbf{P}$, Khabazkhoo $\mathbf{M}$, Ostadimoghaddam H, Doostdar A, Shiralivand E, et al. The prevalence of convergence insufficiency in Iran: a population-based study, 2017; 100 (6): 704-709.

13. Hussaindeen JR, Rakshit A, Singh NK, George R, Swaminathan M, Kapur S, et al. Prevalence of nonstrabismic anomalies of binocular vision in Tamil Nadu: report 2 of BAND study, 2017; 100 (6): 642648 . 
14. Wallace DK. Treatment options for symptomatic convergence insufficiency. Arch Ophthalmol. 2008; 126 (10): 1455-1456.

15. Sharif Z, Mirzajani A, Jafarzadehpur E. Prevalence of convergence insufficiency in a population of university students. J Paramed Sci Rehab. 2014; 3 (1): 47-52.

16. Vaishali RS, Jha KN, Srikanth K. Prevalence of convergence insufficiency between 18 and 35 years and its relation to body mass index. J Ophth Sci Res. 2019; 57 (1): 27-30.

17. Ming-Leung M, Yeo AC, Scheiman M, Chen X. Vergence and Accommodative Dysfunctions in Emmetropic and Myopic Chinese Young Adults. Hindawi J Ophthalmol. 2019; 5904903. https://doi.org/10.1155/2019/5904903

18. Hassan LI, Ibrahim SM, Abdu M, Sharif AM. Prevalence of convergence insufficiency among secondary school students in Khartoum, Sudan. Oman J Ophthalmol. 2018; 11 (2): 129-133.

19. Hashemi H, Nabovati P, Khabazkhoob $\mathbf{M}$, Ostadimoghaddam H, Doostdar A, Shiralivand E, et al. The prevalence of convergence insufficiency in Iran: a population-based study, 2017; 100 (6): 704-709.

20. Ghadban R, Martinez JM, Diehl NN, Mohney BG. The incidence and clinical characteristics of adult-onset convergence insufficiency. Ophthalmology, 2015; 122 (5): 1056-9. Doi: 10.1016/j.ophtha.2014.12.010.

\section{Authors' Designation and Contribution}

Izmal Urooj; Senior Lecturer: Concepts, Design, Literature search, Data analysis, Statistical analysis, Manuscript preparation, Manuscript editing, Manuscript review.

Shari Mussadiq Ali; Optometrist: Concepts, Design, Literature search, Data acquisition, Data analysis, Statistical analysis, Manuscript preparation, Manuscript editing, Manuscript review.

Abdul Ghayas; Optometrist: Concepts, Design, Literature search, Data acquisition, Data analysis, Statistical analysis, Manuscript preparation, Manuscript editing.

Ammara Sheikh; Optometrist: Design, Literature search, Data acquisition, Data analysis, Manuscript preparation.

Maryam Hussain; Optometrist: Design, Literature search, Data acquisition, Manuscript preparation 